Paidéia, 2005, 15(31), 185-193

\title{
ARTHUR RAMOS E ANÍSIO TEIXEIRA NA DÉCADA DE 1930 ${ }^{1}$
}

\author{
Fabíola Sircilli \\ FFCLRP - Universidade de São Paulo
}

Resumo: O artigo busca mostrar o movimento Escola Nova e autores ligados a ele. Foca-se a atuação de Arthur Ramos, médico que trabalhou ao lado de Anísio Teixeira, eminente pensador escolanovista, quando este foi diretor da instrução pública no Distrito Federal, nos anos 30. Ramos, que tinha fortes ligações com a Psicanálise, dirigiu o Instituto de Higiene Mental, órgão da administração municipal na gestão de Teixeira, onde foi instalada uma Seção de Ortofrenia e Higiene Mental. Ramos atuou empregando Freud, Jung e Adler tendo que adequar as teorias psicológicas que dispunha em meios aplicáveis à educação brasileira. Dados indicam que a inserção da psicanálise na educação foi favorecida pelas idéias deweyanas de Anísio Teixeira. Esse estudo é oriundo de pesquisa bibliográfica focada nas obras de Arthur Ramos: "Educação e Psicanálise” e “A criança problema”.

Palavras-chave: Psicanálise; escola nova; educação brasileira.

\section{RAMOS AND TEIXEIRA IN THE 30'S}

\begin{abstract}
This article shows the New School movement and authors related to it. We focus on Arthur Ramos, a doctor who worked along with Anísio Teixeira, an eminent activist, when he was the head of the Public Instruction of the Federal District in the 30's. Ramos, who had strong links with Psychoanalysis, directed the Mental Hygiene Institute that was a department of the municipal administration during Teixeira's management where a Service of Ortofrenia and Mental Hygiene was implemented. There, Ramos applied Freud, Jung and Adler adjusting their psychological theories to the Brazilian education. Data indicates that the application of psychoanalysis to the education was favored by Teixeira's Deweyan ideas. This study has its origin in a research based on Ramos books: "Educação e Psicanálise” and “A criança problema”.
\end{abstract}

Key-words: Psychoanalysis; new school; Brazilian education.

Introdução:O alagoano Arthur Ramos de Araújo Pereira (1903-1946) e o bahiano Anísio Spínola Teixeira (1900-1971) percorreram trajetórias intelectuais distintas, cada qual em seu campo específico de atuação. No início da década de 1930, porém, ambos atuaram em conjunto na área da Educação, embora por um breve período de tempo. Teixeira, então Diretor da Instrução Pública do Distrito Federal, que passou a ser chamada de DepartamentoGeral de Educação e, mais tarde, Secretaria de Educação do governo municipal do Rio de Janeiro, convidou o médico Arthur Ramos a assumir a Seção de Ortofrenia e Higiene Mental do Instituto de Pesquisas Educacionais, IPE (Nunes, 2000). Juntos,

\footnotetext{
${ }^{1}$ Recebido para publicação em 05/04/2005 e aceito em 12/08/2005. ${ }^{2}$ Endereço para correspondência: Fabíola Sircilli, Rua Ramos de Azevedo, 373, Ribeirão Preto-SP, CEP: 14090-180, E-mail: fasircilli@yahoo.com.br
}

colocaram em prática um projeto educacional que privilegiava o estudo de crianças escolarizadas com o objetivo de classificá-las segundo seu potencial intelectual e aptidão, viabilizando tratar aquelas que apresentassem problemas de aprendizagem.

Segundo Nunes (2000), Teixeira acreditava que a identificação das aptidões levaria ao aproveitamento máximo das potencialidades de cada indivíduo, permitindo o crescimento pessoal e, em última instância, a reorganização da sociedade. Tal crença o teria aproximado de Arthur Ramos, que se interessava pelo estudo do modo de vida das classes sociais pobres, no intuito de formular propostas preventivas e corretivas na esfera da vida escolar e familiar.

Embora cada um desses personagens já tenha sido objeto de vários estudos acadêmicos, considera-se que ainda persistem certas lacunas a preen- 


\section{Fabíola Sircilli}

cher, especialmente no que diz respeito à relação entre as concepções filosóficas e educacionais de Anísio Teixeira e a ciência psicanalítica estudada e defendida por Ramos. Interessa compreender os esforços de Arthur Ramos para levar a Psicanálise ao campo educacional, analisando a sua maneira particular de promover a conciliação das idéias psicanalíticas com os projetos educacionais da administração Anísio Teixeira.

No presente trabalho, não se pretende esgotar o assunto, mas apenas fornecer alguns elementos para futuras investigações. Assim, mediante dados oriundos da literatura especializada, procurar-se-á situar os temas considerados relevantes para esse objetivo. Far-se-á um esboço das realizações e idéias de Anísio Teixeira no âmbito do movimento Escola Nova, para, em seguida, posicionar as iniciativas e as concepções de Arthur Ramos. Ao final, serão apresentados os caminhos que podem ser tomados para a continuidade dessa investigação.

\section{A Administração Anísio Teixeira}

A atuação administrativa de Anísio Teixeira na área educacional teve início em Salvador em 1924, ocasião em que respondeu pela reforma do ensino na Bahia, seu estado natal. Embora sem nenhuma experiência prévia no campo da educação, assumiu o cargo de Inspetor-Geral do Ensino a convite do recém empossado governador do estado, Francisco Góes Calmon, a quem havia ajudado a eleger. Sua gestão na Bahia estendeu-se de 1924 a 1929 (Nunes, 2000); mais tarde, em 1932, destacou-se como signatário do Manifesto dos Pioneiros da Educação Nova, documento que propôs outros caminhos políticos e filosóficos para a educação brasileira, segundo Cunha (1997). Desde 1931, Teixeira ocupou o cargo de Diretor Geral do Departamento de Educação do Distrito Federal, afastando-se em 1935 por motivações políticas (Silva, 1998).

Quando teve início a reforma do ensino no Rio de Janeiro, aproximadamente um terço das crianças entre seis e doze anos não freqüentava a escola, em virtude de os sistemas de ensino público e particular estarem saturados. Durante a gestão Teixeira, vinte e nove novas escolas foram construídas; as situadas em bairros periféricos e em localidades prósperas como Copacabana passaram a atender mora- dores pobres, fazendo com que o número de crianças matriculadas crescesse significativamente, indo de 84.539 para 106.707 (Dávila, 2003).

Teixeira implantou uma reforma francamente inspirada no modelo americano. Durante sua administração, transformou a Escola Normal em Instituto de Educação, seguindo os moldes da Universidade Colúmbia, onde havia concluído seu curso de pósgraduação recebendo o título de "Master of Arts" em 1929 (Dávila, 2003). O Instituto passou a ministrar aulas para os níveis primário e secundário, sendo que este último visava preparar alunos para a escola de professores, que era de nível universitário. O curso de formação do magistério incluía Biologia, Pedagogia, Sociologia e Psicologia, esta instituída mais tarde por Lourenço Filho. A proposta não era somente garantir aos professores um diploma de estudos superiores, mas criar diretrizes inovadoras para a prática docente, dentro de um espírito profissional e científico (ibidem).

Uma das maiores inovações da administração anisiana foi o Instituto de Pesquisas Educacionais, IPE, com destacada ênfase na seção de Ortofrenia e Higiene Mental. Os diversos departamentos do IPE empregaram muitos "estudiosos da raça”, tornandose um referencial no assunto, e estipularam que as práticas antropológicas e médicas e as teorias psicológicas ficariam associadas aos programas do Departamento de Educação (ibidem).

Em suma, como mostram Lopes e Galvão (2000), Anísio Teixeira canalizou esforços no intuito de reorganizar o ensino público, ao mesmo tempo em que enfatizou a importância da formação de professores. Durante sua gestão procurou ampliar a influência da escola na sociedade, transferir a responsabilidade das questões educacionais do governo para os educadores, definir prioridades e metas criando novos saberes, quebrar barreiras hierárquicas ditadas por uma severa divisão social. Essas iniciativas geraram conflitos, seja com órgãos do governo, com grupos católicos e esquerdistas, o que mostra o caráter polêmico de sua gerência. Ele encarnou o sentimento de mudança que havia no país e, assim, reuniu em torno de si colaboradores oriundos de diferentes correntes intelectuais que, como ele, aspiravam a mudanças.

Foi no âmbito dessa reforma do ensino 
conduzida por Teixeira que Arthur Ramos foi para o Distrito Federal, convidado a assumir o cargo de chefe da primeira clínica de higiene mental no Brasil e, possivelmente da América Latina, vinculada a um projeto educacional (Abrão, 2001). Em correspondência trocada entre ambos em novembro de 1939 (Barros, 2000), Ramos reconheceu a importância de Anísio Teixeira para a criação e realização desse projeto.

\section{O Movimento Educacional Renovador e o Higienismo}

A reforma Anísio Teixeira integrou o movimento educacional renovador conhecido como Escola Nova, e o trabalho de Arthur Ramos no Distrito Federal foi feito em consonância com os ideais escolanovistas (Abrão, 2001). Essa afirmação leva à necessidade de compreender o escolanovismo, cujas raízes situam-se nos anos de 1920, quando o discurso vigente enfatizava a necessidade de o Brasil caminhar para mudanças educacionais que o colocassem no mesmo nível de outros países mais desenvolvidos. A idéia em voga era que somente um novo projeto de escola levaria ao progresso toda a sociedade brasileira (Cunha, 1999a).

A Escola Nova marcou o cenário nacional nas décadas de 1930, 1940 e 1950, com propostas inovadoras em oposição ao ensino tradicional existente. Com ela, a ciência ganhou espaço norteando as diretrizes escolares e agregando conhecimentos da Psicologia e da Sociologia às práticas pedagógicas de então. O movimento renovador surgiu sustentado nas idéias de modernização iniciadas já no século XIX, quando o país passou do sistema escravocrata ao trabalho livre e ocorreu a instalação do regime republicano (Cunha, 1999a).

Na passagem do século, pouca coisa do que acontecia no mundo passava despercebida aos intelectuais brasileiros, que se mostravam profundamente atualizados com as obras publicadas no exterior, veiculavam um discurso modernizador sintonizado com as discussões internacionais e a profunda transformação de idéias (Lopes, 2002). No Rio de Janeiro, o período de reformas educacionais teve seu início marcado por dois eventos em 1917. O primeiro diz respeito à expedição realizada por um grupo de médicos para mapear as condições de saúde no interior do país. Em seu retorno, Arthur Neiva e Belisário
Penna publicaram um relatório apontando a necessidade da criação de um ministério federal de educação e saúde. O segundo fato que merece destaque deu-se quando Afrânio Peixoto, proeminente na área de medicina legal e estudioso das relações entre as raças, clima e degeneração nos trópicos, assumiu a direção do Departamento de Educação da cidade. Peixoto acreditava que alguns indivíduos eram geneticamente inclinados ao crime e, dessa forma, projetou uma ampla reforma do ensino que refletia a crença de que a degeneração racial poderia ser revertida por intermédio de melhorias científicas na saúde e na educação (Dávila, 2003). Peixoto desenvolveu teorias que aproximavam o criminoso, a criança, a mulher e os povos ditos selvagens, ou seja, os excluídos da história (Lopes, 2002).

Afrânio Peixoto tornou-se figura importante e indispensável para qualquer movimento na área da educação, notabilizando-se por conceitos em que separava a educação nacional em aspectos masculinos e femininos; era a favor de um "taylorismo educativo" e classificava o ensino primário como tarefa exclusiva para as mulheres; propunha a co-educação, para prevenir a misoginia, e era simpático à implantação de jardins de infância e escolas maternais. Além disso, considerava o casamento precoce nocivo à saúde dos cônjuges, a sua fecundidade e à vitalidade dos filhos, o que o levou a propor regras para uniões eugênicas, pregando a educação física como forma de combater a sexualidade precoce nos jovens, o que considerava fonte de enfraquecimento físico e moral (Lopes \& Galvão, 2000).

O movimento em prol da educação e higienização de corpos e mentes contava com o respaldo de médicos, bacharéis e educadores. Em 1927, Miguel Couto, então presidente honorário da Associação Brasileira de Educação, ABE, fundada em 1924, decretou haver um só problema nacional: a educação do povo (Lopes, 2002). Por meio da escola, esperava-se conduzir o país a reformas que gerassem progresso e desenvolvimento, colocando-o na condição de "nação moderna". No campo da educação, modernidade significava incorporar métodos científicos às práticas pedagógicas, como o emprego de sistemas de mensuração que oferecessem, com exatidão, estatísticas quanto ao número de escolas, alunos e professores. 


\section{Fabíola Sircilli}

A relação entre Afrânio Peixoto e Anísio Teixeira era muito próxima, tanto do ponto de vista pessoal quanto profissional, e se intensificou com a chegada de Arthur Ramos ao Rio. Os três mantiveram um relacionamento de profunda colaboração em prol das reformas educacionais. Em 1935, ano em que se afastaria da administração pública, Teixeira nomeou Afrânio Peixoto para o cargo de reitor da Universidade do Distrito Federal (Lopes, 2002).

\section{O Discurso Educacional Renovador}

No âmbito do escolanovismo que se desenvolveu no Brasil, predominou um discurso racionalizador que se traduzia no emprego dos mais avançados recursos científicos no campo educacional. O método taylorista, baseado na organização racional do trabalho, buscando alcançar o máximo de rendimento com o mínimo de tempo e esforço, foi sugerido para controlar o trabalho dos professores, levando a um modelo de eficiência assemelhado ao das fábricas (Cunha, 1999b).

No que diz respeito às relações da escola com a comunidade, manifestava-se o mesmo espírito racionalizador, colocando a escola como o espaço privilegiado de socialização e normalização da ordem vigente. A família era vista como inadequada para educar os filhos; medidas higiênicas foram implementadas no intuito de manter os corpos dos alunos dentro dos padrões de limpeza; suas mentes seriam estudadas por meio de apurados instrumentos psicológicos e psicopedagógicos, e os professores seriam treinados para usar as técnicas mais recentes da pedagogia (Cunha, 1999a).

Em 1931, a revista Escola Nova lançou um fascículo dedicado à iniciação no estudo de testes, cuja função era avaliar objetivamente o trabalho de cada docente e as diretrizes pedagógicas das escolas. Para isso seriam aplicadas técnicas científicas que desvendassem os fenômenos biológicos e o determinismo dos fenômenos sociais. A técnica científica devia atingir todos os ramos de atividade, pois permitia verificar os meios mais seguros e econômicos a serem postos em prática, os materiais empregados e suas funções, bem como aquilatar a obtenção dos objetivos pretendidos.

Em suma, pretendia-se que o conhecimento e as técnicas científicas trouxessem para o campo educacional a compreensão das mentes infantis e avaliações mais precisas do trabalho dos professores, pois até então - diziam os críticos - critérios meramente subjetivos eram adotados nessas áreas. Pesquisas sobre inteligência, personalidade e capacidade começaram a serem feitas para classificar e tornar possível mudar o que fosse indesejável. A pedagogia seria desenvolvida com base na ciência, tornando-se experimental, mediante avaliações precisas baseadas em critérios científicos e impessoais. De posse dos resultados dos testes, o ensino poderia ser moldado às idades e fases do aprendizado, como apregoava Lourenço Filho (1931).

$\mathrm{O}$ Teste $A B C$, criado por Lourenço Filho a partir de pesquisas realizadas na escola-modelo anexa à Escola Normal de Piracicaba em 1925, exemplifica essa mentalidade (Magnani, 1997). Seu objetivo era medir a maturidade para a aprendizagem da leitura e escrita, permitindo caracterizar a maturidade educacional. Em essência, os alunos, que se mostrassem capazes de identificar e escrever palavras contidas em um determinado grupo de objetos e tivessem habilidade motora para realizar desenhos geométricos, eram classificados como maduros. O $A B C$ foi o principal instrumento usado para selecionar alunos aptos a freqüentar a escola, tendo sido amplamente aplicado em escolas do Rio de Janeiro e São Paulo a partir de 1928 e nas décadas seguintes (Dávila, 2003). Em grupos escolares de São Paulo, foi feita em 1931 a maior tentativa de organização psicológica com a aplicação do $A B C$ para mais de 20 mil crianças, cujo resultado foi o planejamento de 468 classes diferenciadas (Lourenço Filho, 1931). No Distrito Federal operação semelhante já havia sido realizada com 305 crianças das escolas públicas do sétimo distrito escolar (Nunes, 2000).

Segundo Cunha (1999a), esse espírito racionalizador teria sido uma das tendências do discurso escolanovista no Brasil entre 1930 e 1960, caracterizada como promotora da subordinação do indivíduo às ordenações sociais. Embora dominante, não foi, porém, a única tendência, uma vez que no período desenvolveu-se também uma visão norteada pelo ideal de equilíbrio entre indivíduo e sociedade, em que a educação era vista como um empreendimento que satisfizesse às demandas sociais gerando o progresso pretendido e que, ao mesmo tempo, respeitasse as 
particularidades e necessidades pessoais. Nessa última tendência, Cunha situa Anísio Teixeira.

As concepções filosóficas e educacionais de Teixeira eram marcadamente influenciadas pelo filósofo-educador norte-americano John Dewey, para quem a educação deveria manter o equilíbrio entre o homem e suas particularidades psicológicas, de um lado, e as exigências da sociedade em que vivia, de outro. Dewey via a escola como um meio de integrar o homem à coletividade, respeitando as aptidões naturais e singularidades de cada indivíduo, priorizando um ensino que respeitasse a lógica da criança e seu desenvolvimento psicológico (Cunha, 1999a). Em 1934, Teixeira lançou o livro Educação progressiva, obra que o projetou como pensador deweyano.

\section{Arthur Ramos e a Psicanálise}

Arthur Ramos iniciou o curso de medicina em 1921 na Faculdade de Medicina da Bahia, concluindo em 1926 com a defesa da tese "Primitivo e Loucura”. No ano seguinte foi contemplado com o prêmio Alfredo Brito da mesma universidade (Abrão, 2001). Além de fundador e chefe do Serviço de Higiene Mental do Departamento de Educação do Rio de Janeiro, Ramos foi ainda catedrático de Antropologia e Etnologia da Universidade do Brasil; chefe do Departamento de Ciências Sociais da UNESCO; organizador e chefe do Serviço de Neuropsiquiatria do Serviço Central de Escolas/Hospitais do Departamento de Educação do Rio de Janeiro; professor de Psicologia Social de Universidade do Distrito Federal; médico legista do Serviço Médico Legal do Estado da Bahia - Instituto Nina Rodrigues; médico assistente do hospital São João de Deus, Bahia.

A obra de Ramos é extensa, incluindo Estudos de Psicanálise (1931), Freud, Adler, Jung (1933), Psiquiatria e Psicanálise (1933), Educação e Psicanálise (1934), Introdução à Psicologia Social (1936), Loucura e Crime (1937), A criança problema (1939), entre outros. Seu interesse pela Psicanálise começou quando ainda era estudante de Medicina e é atribuído, em parte, ao seu espírito desbravador e à crença de que em tal teoria residiam soluções para vários problemas da realidade brasileira, aparentemente insolúveis. Sua simpatia pelo estudo da infância foi revelada em seu trabalho "Os suicídios de crianças (Ensaio Psicológico)”, de 1928, apresen- tado à Sociedade de Medicina Legal, Criminologia e Psiquiatria da Bahia.

Na ocasião, Ramos exercia a função de docente da clínica psiquiátrica na Faculdade de Medicina da Bahia e era o segundo secretário da referida Sociedade bahiana, estando prestes a ocupar o cargo de médico-legista no Instituto Nina Rodrigues. A forma como ele dissertou sobre o suicídio infantil não deixou dúvidas quanto à sua aprovação das teorias freudianas (Silva, 1998). Antes de se mudar da Bahia, liderou em Salvador um grupo de médicos com o intuito de divulgar e discutir teorias psicanalíticas (Menezes, 2003).

A aproximação de Ramos com a Psicanálise deve ser entendida mediante o percurso de inserção das teorias psicanalíticas no Brasil, em particular no campo da educação escolar, dada a relevância histórica da Seção de Ortofrenia e Higiene Mental por ele dirigida. A introdução da Psicanálise no Brasil, nos primeiros anos do século $\mathrm{XX}$, não ocorreu tranqüilamente, mas realizou-se em meio a disputas ideológicas que culminaram na utilização de vários de seus preceitos em diferentes áreas.

A primeira menção ao nome de Freud no Brasil foi feita em 1899, ano de publicação da obra A interpretação dos sonhos. Juliano Moreira, médico bahiano formado em Psiquiatria dinâmica na Europa, citou-o em uma de suas aulas na Escola de Medicina da Bahia (Lopes, 2002). Não por coincidência, a Medicina viria a ser o meio pelo qual os pioneiros do movimento psicanalítico tentariam introduzir as teorias de Freud, iniciativa que acabou por fracassar.

Segundo Mokrejs (1988), Durval Marcondes, fundador da primeira Sociedade de Psicanálise da América Latina, acreditava que tais teorias muito beneficiariam o trabalho dos médicos, se estes levassem em conta os transtornos psicológicos de seus pacientes. Marcondes também chamou a atenção da classe médica para as vantagens do uso de teorias psicanalíticas para intervir nos conflitos educativos, em casos de crianças com distúrbios de caráter. Em 1934, ele se empenhou pela formação da Universidade de São Paulo e criação das cátedras de Psicologia e Psicanálise no curso de Medicina.

Os opositores de tal iniciativa, porém, foram numerosos, por considerar as teses freudianas uma perigosa ameaça ao prestígio e credibilidade da clas- 
se médica da época. Entre eles, Antônio Carlos Pacheco e Silva que, não concordando com os princípios da Psicanálise, fechou as portas da Faculdade de Medicina de São Paulo para a doutrina de Freud e seus seguidores. Ele foi aprovado em concurso público para a cátedra de Psiquiatria em 1936, derrotando Marcondes, que também concorreu à vaga (Abrão, 2001).

Assim, só restou à Psicanálise integrar o meio acadêmico por intermédio do Instituto de Higiene Mental, dirigido por Arthur Ramos (Facchinetti, 2000). Isso foi possível graças à aliança da psiquiatria com 0 poder público, visando à elaboração de um projeto preventivo de higiene pública nos centros urbanos, incluindo os escravos recém libertos, os índios, os brancos pobres e os imigrantes (Lopes, 2002).

O livro Educação e Psicanálise (Ramos, 1934) foi publicado no ano em que Ramos atendeu ao convite de Anísio Teixeira para integrar sua administração,o que pode fornecer a medida de suas idéias quanto ao tema no momento preciso em que se vinculou ao projeto escolanovista anisiano. Nessa obra, ele expõe sua visão das principais teorias psicanalíticas aplicadas à educação, explica a teoria de Freud sobre sexualidade infantil, a Psicologia individual de Adler, faz considerações sobre a prática da análise infantil, a pedanálise, e referências ao trabalho de Anna Freud, Melanie Klein, Marie Bonaparte e Sophie Morgenstern, entre outros, com o intuito de divulgar as diferentes escolas psicanalíticas e suas possíveis contribuições à prática pedagógica.

$\mathrm{O}$ autor argumenta que ao educador preparado pela Psicanálise cabe a tarefa de ajudar o aluno com dificuldades, deixando os casos mais graves para os psicanalistas. Recomenda que o ideal seria haver uma formação psicanalítica para todos os responsáveis pelo desenvolvimento mental da criança, incluindo pais e educadores. No primeiro capítulo do livro, intitulado “A escola nova e a Psicanálise”, Ramos evoca as correntes escolanovistas oriundas de John Dewey e Kilpatrick, sintetizadas por Anísio Teixeira em seu livro Educação Progressiva. Por fim, ele enumera os avanços da Psicanálise na Pedagogia brasileira, citando o trabalho de vários colegas e transcrevendo a dedicatória recebida de Anísio Teixeira por ocasião do lançamento de Educação Progressiva, na qual o educador diz ser a Psicanálise "uma das ciên- cias que mais devem concorrer para a educação” (Ramos, 1934).

\section{Arthur Ramos e a Higiene Mental}

O livro A criança problema (Ramos, 1939), por sua vez, foi publicado em 1939, ano em que terminou a experiência de Ramos na administração do Distrito Federal. Na obra, ele faz um esboço do movimento de higiene mental no Brasil e no mundo, descreve o trabalho da Seção que dirigiu no Distrito Federal, relata as causas que originam as dificuldades escolares das crianças, fazendo a caracterização de vários casos atendidos na clínica, transcrevendo os registros dos pacientes e as explicações quanto à etiologia de cada distúrbio, bem como os encaminhamentos e soluções oferecidos. Para ele, a análise desses casos deveria ser feita em conjunto com o exame do lar e da escola, argumentando ser este um ponto predominante da Escola Nova. Sugere que os pais busquem compreender objetivamente os problemas dos filhos, assumindo suas responsabilidades na formação psicológica deles.

Segundo explica Ramos (1947), o movimento da Higiene Mental foi significativo no Brasil e no exterior, sendo seu objetivo inicial a "prevenção das doenças mentais”, meta que logo se ampliou. Da prevenção de doenças passou ao estudo do homem normal em relação aos seus desajustamentos, sejam eles de ordem social, emocional, doméstico ou cultural. Ligas e Conselhos foram fundados no Canadá, em 1918; na França, em 1920; na Bélgica, em 1921; na Inglaterra, em 1923, ano no qual o serviço foi fundado também no Brasil pelo psiquiatra Gustavo Riedel.

Além das já citadas, outras clínicas vieram a funcionar em outras localidades, como África do Sul, Província do Cabo, Espanha, Itália, Suíça, Alemanha, Hungria, Nova Zelândia e Bulgária. Em 1922 foi organizado o Comitê Internacional de Higiene Mental, que planejou e realizou o primeiro Congresso Internacional de Higiene Mental em Washington, em 1930; o segundo foi em Paris no ano de 1937; o terceiro congresso foi agendado para ocorrer no Rio de Janeiro.

Sagawa mostra (2002) que o objetivo do movimento de Higiene Mental era ajustar o indivíduo ao seu grupo social, razão pela qual a infância tornou-se o seu foco inicial. Seus adeptos acreditavam 
que é nessa etapa da vida que as características do caráter de cada um começavam a se formar e, portanto, ajustar a criança ao seu meio significava prepará-la para a vida adulta.

Vale lembrar que o movimento de Higiene Mental no Brasil teve duas vertentes. A primeira, definida como "política", era eugenista e visava a "purificação da raça” e a prevenção de doenças como o alcoolismo. A segunda foi criada e desenvolvida por Durval Marcondes em São Paulo e por Arthur Ramos no Rio de Janeiro, visando atuar em escolas primárias, no atendimento às crianças que necessitassem de intervenção psicológica, para isso aplicando conhecimentos da Psicanálise (Abrão, 2001).

A Seção de Ortofrenia e Higiene Mental chefiada por Ramos começou a funcionar em janeiro de 1934, sendo a primeira a atuar em conjunto com as escolas do Rio de Janeiro. As chamadas clínicas de direção e orientação da criança, psico-clínicas ortofrênicas ou simplesmente clínicas de higiene mental, eram compostas por técnicos distribuídos em quatro divisões ou setores especiais: social (serviços sociais, professores, visitadores), psicológico (exame psicológico de fundo mental e aptidões pedagógicas), médico (exame de fundo orgânico) e psiquiátrico (exame mais largo de todos os desajustamentos emocionais e psicológicos, desde os casos fronteiriços, até os aspectos mais graves da neurose e da psicose), como descreve Arthur Ramos (1939).

Para Ramos, a tarefa das Clínicas se completa com o exame do lar e, em seguida, da escola, configurando um trabalho de mútua cooperação entre as partes. Ramos propôs a criação de Círculos de pais e mães para colaborarem com o Instituto, de maneira a eliminarem os maus hábitos da primeira e segunda infância. Também estudou as características das moradias sobre a personalidade da criança, as atitudes dos pais, dos mais rigorosos aos mais liberais, e a influência dos avós (Nunes, 2000).

Após constatar que $90 \%$ das crianças consideradas "anormais", quando comparadas aos ditos "normais", eram na verdade crianças sem qualquer tipo de anomalia mental, Ramos criou a denominação “criança problema” em substituição à terminologia vigente, englobando assim todas as crianças com dificuldade de adaptação ao ambiente, seja o lar, seja a escola. Com isso, privilegiou um trabalho de preven- ção e correção de comportamentos potencialmente fora dos padrões.

A denominação “criança problema” muito contribuiu para a educação infantil, pois redefiniu o até então empregado conceito de "anormalidade", o qual era fundamentado em resultados de testes de inteligência (Mokrejs, 1987). Ramos considerava que essas crianças haviam sido "anormalizadas" por seu meio, a partir do ponto de vista do adulto, numa atitude inconscientemente sádica de pais e educadores. Essa tipologia foi mais tarde atualizada, em trabalhos da década de 1940, inspirados nas teorizações sobre crianças-problema feitas por Ramos, provavelmente o primeiro a elaborar teorias sobre o assunto (Nunes, 2000).

Segundo Ramos, nas clínicas deveriam ser empregados métodos combinados, sem dar preferência a nenhum em particular, dependendo as combinações das particularidades de cada caso. Eram aplicados os métodos de observação incidental, fragmentos biográficos, observação sistemática, questionário, história de casos, "tests” e experimentação. Junto a esses, eram empregados conceitos derivados do movimento psicanalítico das escolas de Freud, Adler e Jung. Arthur Ramos considerava que essas escolas analíticas eram complementares no atendimento às crianças.

A seção de Ortofrenia e Higiene Mental do Rio de Janeiro funcionou durante cinco anos, de 1934 a 1939, e totalizou o atendimento a duas mil crianças. Essa experiência foi tão bem sucedida que Ramos planejava oferecer seus serviços a toda a população do Distrito Federal. Já havia iniciado uma clínica de pré-escolares na escola “General Trompowiski” com resultados promissores, e o próximo passo seria tratar do adolescente e produzir um estudo sobre a higiene mental nos regimes de internato. Ademais, desenvolviam-se projetos sobre orientação profissional em novas bases científicas, sobre o papel do cinema na psique infantil, desenhos e jogos e sua função na higiene mental. Também estava nos planos um estudo dos distúrbios da linguagem e aptidões especiais, ao mesmo tempo em que os "anormais" propriamente ditos, e não as chamadas "crianças problemas", seriam objeto de um tratamento à parte.

Os trabalhos que vinham sendo desenvolvidos de forma frutífera, e que em breve seriam larga- 


\section{Fabíola Sircilli}

mente ampliados, sofreram severas restrições devido ao golpe de estado de Getúlio Vargas, que instalou o Estado Novo e proclamou uma nova Constituição em 1937. Como descreve Ramos (1939), em virtude desse quadro político uma nova concepção de educação passou a vigorar, cerceando a liberdade e as iniciativas dos educadores, fazendo com que o trabalho do Instituto se tornasse inviável. Contribuíram também para isso a aproximação da Segunda Guerra Mundial e as condições deficitárias do Brasil, em especial no Rio de Janeiro, com o colapso no setor da alimentação, a crise de habitações, os índices alarmantes de mortalidade e delinqüência infantis e o problema do menor abandonado. Após alguma resistência perante a nova ordem em vigor, só restou à instituição fechar suas portas.

\section{Considerações Finais}

A importância de Arthur Ramos para a história da educação no Brasil parece evidente por sua relevância como teórico, seja pela proposição do conceito de "criança problema", seja por seus estudos versando sobre Psicanálise e Educação, nos quais defende a aplicação de teorias psicanalíticas na escola, não como método para substituir os já existentes, mas como instrumento de auxílio na solução dos problemas da prática educacional. No plano das realizações administrativas de Ramos, que contribuíram para seus desenvolvimentos teóricos, é inegável o valor histórico do Instituto de Higiene Mental, no qual procurou viabilizar o proposto intercâmbio entre várias correntes psicanalíticas e a prática educacional.

Por isso, considera-se que compreender em maior profundidade as idéias de Ramos é imprescindível para melhor elucidar o movimento educacional renovador desenvolvido no Brasil, em especial no tocante à administração Anísio Teixeira no Distrito Federal. Para a continuidade dessa investigação, julgase procedente conhecer em que medida se deu a junção entre a visão psicanalítica e educacional de Ramos e o projeto educacional de Teixeira, bem como entre as concepções de ambos e o movimento higienista.

Uma hipótese a ser considerada é que os planos de Ramos tenham sido favorecidos por Teixeira não apenas no aspecto político, ou seja, pela criação de espaço administrativo para a inserção da psicaná- lise no campo educacional. É possível que tenha havido uma interlocução teórica mais refinada entre as concepções psicanalíticas do primeiro e a filosofia deweyana do segundo, no intuito de criar condições concretas para responder aos problemas sociais e educacionais de sua época. A continuidade dessa pesquisa poderá revelar, em suma, como se deu a conciliação entre as idéias de Arthur Ramos e visão educacional socializadora de Anísio Teixeira.

\section{Referências Bibliográficas}

Abraão, J. L. F. (2001). A história da Psicanálise de crianças no Brasil. São Paulo: Escuta.

Barros, L. O. C. (2000). Arthur Ramos e as dinâmicas sociais de seu tempo. Maceió: Edufal.

Cunha, M. V. (1997). O discurso educacional renovador no Brasil (1930-1960): Um estudo sobre as relações entre escola e família. Tese de LivreDocência, Faculdade de Ciências e Letras, Universidade Estadual Paulista, Araraquara.

Cunha, M. V. (1999a). John Dewey, a outra face da Escola Nova no Brasil. Em P. Ghiraldelli Júnior (Org.), O que é filosofia da educação? (pp.247-264) Rio de Janeiro: DP\&A.

Cunha, M. V. (1999b). Três versões do pragmatismo deweyano no Brasil dos anos cinqüenta. Revista da Faculdade de Educação, 25 (2), 39-55.

Dávila, J. (2003). Diploma of Whiteness: Race and Social Policy in Brazil, 1917-1945. Durham/Londres: Duke University Press.

Facchinetti, C. (2000). Deglutindo Freud: Histórias da digestão do discurso psicanalítico no Brasil. Tese de doutorado, Instituto de Psicologia, Universidade Federal do Rio de Janeiro. Texto recuperado 15 abr. 2003: http://www.gradiva.com.br/ deglutindo.html.

Lopes, E. M. T. (2002). A psicanálise aplicada às crianças do Brasil: Arthur Ramos e a "criança problema”. Em M. Freitas; M. Kuhlmann Júnior (Orgs.), Os Intelectuais na história da infância (pp. 319343). São Paulo: Cortez.

Lopes, E. M .T. \& Galvão, A.M.O. (2000). História da Educação. Rio de Janeiro: DP\&A. 
Lourenço Filho, M. B. (1931). Os testes. Escola Nova, 2, n 3/4 - mar-abr, 253-259.

Magnani, M. R. M. (1997). Testes ABC e a fundação de uma tradição: alfabetização sob medida. Em C. Monarcha (Org.), Lourenço Filho: outros aspectos, mesma obra (pp. 59-90). Campinas: Mercado de Letras.

Menezes, M. O. (2003). A Psicanálise na Bahia (1926-1937): os estudos de Arthur Ramos sobre a loucura, educação infantil e cultura. Dissertação de Mestrado, Universidade Federal da Bahia e Universidade Estadual de Feira de Santana.

Mokrejs, E. (1987). Psicanálise e Educação. Arthur Ramos: Um episódio da história da educação no Brasil. Revista da Faculdade de Educação, 13 (1), 91-104.

Mokrejs, E. (1988). Durval Marcondes: o primeiro capítulo da Psicanálise e da Psicopedagogia em São Paulo. Revista da Faculdade de Educação, 14 (2), 193-209.

Nunes, C. (2000). Anísio Teixeira: a poesia da ação. Bragança Paulista: EDUSF.

Ramos, A. (1931). Estudos de Psicanálise. Salvador: Casa Editora.

Ramos, A. (1933 a). Freud, Adler, Jung. Rio de Janeiro: Editora Guanabara.

Ramos, A. (1933 b). Psiquiatria e Psicanálise. Rio de Janeiro: Editora Guanabara.

Ramos, A. (1934). Educação e Psicanálise. São Paulo: Nacional.

Ramos, A. (1936). Introdução à Psicologia Social. Rio de Janeiro: CEB.

Ramos, A. (1937). Loucura e Crime. Porto Alegre: Globo.

Ramos, A. (1947). A criança problema. Rio de Janeiro: Casa do Estudante do Brasil (Trabalho original publicado em 1939).

Sagawa, R. Y. (2002). Durval Marcondes. Rio de Janeiro: Imago. (Pioneiros da Psicologia Brasileira, 11).

Silva, A. S. R. (1998). Cuidando do futuro do Brasil: infância, educação e higiene mental na obra de Arthur Ramos. Dissertação de Mestrado, Universidade Federal do Rio de Janeiro, Instituto de Psiquiatria, Rio de Janeiro. 